\title{
Comparing Pharmacological Modulation of Sensory Gating in Healthy Humans and Rats: The Effects of Reboxetine and Haloperidol
}

\author{
Louise Witten ${ }^{*, 1,2}$, Jesper Frank Bastlund', Birte Y Glenthøj ${ }^{2}$, Christoffer Bundgaard ${ }^{3}$, Björn Steiniger-Brach ${ }^{4}$, \\ Arne Mørk' and Bob Oranje ${ }^{2,5}$ \\ 'Synaptic Transmission I, H. Lundbeck A/S, Valby, Denmark; ${ }^{2}$ Center for Clinical Intervention and Neuropsychiatric Schizophrenia Research (CINS). \\ Center for Neuropsychiatric Schizophrenia Research (CNSR), Copenhagen University Hospital, Psychiatric Center Glostrup, Glostrup, Denmark; \\ ${ }^{3}$ Discovery DMPK, H. Lundbeck A/S, Copenhagen-Valby, Denmark; ${ }^{4}$ Medical Affairs-Addiction Disorders, H. Lundbeck A/S, Valby, Denmark; \\ ${ }^{5}$ Department of Psychiatry, Brain Center Rudolf Magnus, University Medical Center Utrecht, Utrecht, The Netherlands
}

Sensory gating is the brain's ability to filter out irrelevant information before it reaches high levels of conscious processing. In the current study we aimed to investigate the involvement of the noradrenergic and dopaminergic neurotransmitter systems in sensory gating. Furthermore, we investigated cross-species reliability by comparing effects in both healthy humans and rats, while keeping all experimental conditions as similar as possible between the species. The design of the human experiment $(n=21)$ was a double-blind, placebocontrolled, cross-over study where sensory gating was assessed following a dose of either reboxetine ( $8 \mathrm{mg})$, haloperidol (2 mg), their combination or placebo at four separate visits. Similarly in the animal experiment sensory gating was assessed in rats, $(n=22)$ following a dose of reboxetine $(2 \mathrm{mg} / \mathrm{kg})$, haloperidol $(0.08 \mathrm{mg} / \mathrm{kg})$, their combination or placebo. The sensory gating paradigms in both experiments were identical. In humans, we found significantly reduced P50 suppression following separate administration of reboxetine or haloperidol, while their combined administration did not reach statistical significance compared with placebo. In the rats, we found a similar significant reduction of sensory gating (N40) following treatment with haloperidol and the combination of haloperidol and reboxetine, but not with separate reboxetine treatment, compared with placebo. Our study indicates that even when experimental conditions are kept as similar as possible, direct human to rat cross-species translation of pharmacological effects on sensory gating is challenging, which calls for more focussed research in this important translational area.

Neuropsychopharmacology (2016) 4I, 638-645; doi:I0.1038/npp.2015.194; published online 19 August 2015

\section{INTRODUCTION}

Humans, and many other species, are constantly subjected to stimuli and impressions from their surroundings. Although the brain is a multifaceted organ, it cannot possibly attend to all of these stimuli and therefore filtering mechanisms have evolved to help ensure that only relevant information reaches the higher brain functions. One way believed to assess the brain's ability to suppress irrelevant incoming information, commonly referred to as sensory gating, is to subject an individual to a, so-called, P50 suppression paradigm: in a typical paradigm, two identical auditory stimuli are presented in close temporal proximity (usually $500 \mathrm{~ms}$ ). In healthy humans the brain's response to the second (testing) stimulus is normally reduced compared with its response to the first (conditioning) stimulus, usually assessed with

*Correspondence: L Witten, Synaptic Transmission, H. Lundbeck A/S, Ottiliavej 7-9, Valby DK-2500, Denmark, Tel: 004521828279 ,

E-mail: Low@lundbeck.com

Received 26 January 2015; revised 20 May 2015; accepted 10 June 20I5; accepted article preview online I July 2015 electroencephalography (EEG; reviewed by Light and Braff, 1999). In humans, it is mainly the P50 event-related potential (ERP, a positive deflection seen in the EEG $\sim 50 \mathrm{~ms}$ after a response-eliciting stimulus) also sometimes referred to as the P1 amplitude that is scored to express sensory gating (Chang et al, 2011). However, in addition the succeeding N100 (or $\mathrm{N} 1$, a negative ERP at $100 \mathrm{~ms}$ ) and P200 (or P2) have been used to assess sensory gating (Boutros et al, 1999), although there is different underlying neural activity involved (Boutros et al, 2004; Brockhaus-Dumke et al, 2008; Oranje et al, 2006).

Similar to humans, other animal species such as primates, cats, rabbits, rats, and mice display sensory gating. The rat equivalent of the human P50 has been subjected to much scrutiny; while some believe it to be the P13 (P1; Miyazato et al, 1999) others believe it to be the N40 (N1; Mears et al, 2006). The discussion may be related to the fact that the pattern of rat ERPs elicited by a simple auditory stimulus is remarkably similar to that in humans, with more or less the only exception being that the ERP latencies are $\sim 60 \%$ shorter than those in humans (Adler et al, 1982; Siegel et al, 2003).

Extensive research has shown disrupted P50 gating in patients with schizophrenia compared with healthy controls, 
whether patients were medicated (Adler et al, 1982; Bramon et al, 2004; Nagamoto et al, 1989) or antipsychotic naive, first episode patients (Brockhaus-Dumke et al, 2008; Oranje et al, 2013). Similarly, deficits in N1 gating have been reported in schizophrenic patients compared with healthy controls (Boutros et al, 1999; Brockhaus-Dumke et al, 2008). It should be noted however, that it is difficult to interpret the consequences of deficient P50 suppression in patients with schizophrenia, since not all patients with low P50 gating show perceptual anomalies (Jin et al, 1998).

Evidence is accumulating for involvement of dopaminergic (eg, Csomor et al, 2008; Oranje et al, 2002) as well as noradrenergic (eg, Adler et al, 1994; Baker et al, 1990; Hammer et al, 2007) neurotransmission in healthy sensory gating. In addition, in a recent clinical study from our laboratory, we showed that the specific noradrenergic $\alpha 2$-agonist clonidine alleviated sensory-as well as sensorimotor gating deficits in schizophrenia patients (Oranje and Glenthoj, 2013a, b).

Given all of the above, the current study was designed to first determine the equivalents of human P50 gating in rats, and to investigate whether these rat equivalents would respond in the same way to pharmacological challenges as human P50 gating does. Finding the correct equivalents of human P50 gating in rats is important because it may facilitate translational research and drug development in schizophrenia. The pharmacological challenges consisted of the specific noradrenaline reuptake inhibitor reboxetine and the antipsychotic haloperidol (predominantly a dopaminergicD2 receptor antagonist), both administered separately, as well as combined. The hypothesis was that all three pharmacological challenges would disrupt gating in both species.

\section{MATERIALS AND METHODS}

\section{General}

The human study was approved by the Ethics committee (H-3-2010-098) of the Capital region, Copenhagen, with regard to the ethical principles for medical research involving human subjects as stated in the Declaration of Helsinki Principles (amendment of Washington, 2002). Similarly, the animal study was carried out in accordance with the European Communities Council Directive (86/609/EEC) for the care and use of laboratory animals and the Danish legislation regulating animal experiments. The Danish Animal Experimentation Inspectorate approved the protocols (journal no. 2004/561-798 and 2009/561-1596).

\section{Human Study}

Subjects. Twenty-one healthy male volunteers recruited from the capital region of Copenhagen through the web page www.forsøgsperson.dk participated in the study. Written informed consent was obtained from all subjects before enrolment, following written and oral information on the project.

All subjects were aged between 18-30 years, mean age was 23.4 years $(\mathrm{SD}=2.8)$, mean weight was $78.5 \mathrm{~kg}(\mathrm{SD}=7.7)$, while mean height was $185 \mathrm{~cm}(\mathrm{SD}=8.9)$, resulting in a mean BMI of $22.9(\mathrm{SD}=1.8)$. Of the 21 recruited participants, 4 were tobacco smokers. Mental health history and absence of a history of drug and alcohol abuse were ascertained by the use of the Schedule for Clinical Assessment in Neuropsychiatry, version 2.0 (Wing et al, 1990). Furthermore, an electrocardiogram was taken prior to the participation in the experiment to ensure healthy heart function. Exclusion criteria were the use of current medication, history of neurological or psychiatric illness, psychiatric illness in a first degree relative, alcohol or drug abuse, and previous participation in a psychophysiological assessment. Urine samples were taken at each visit to test for the absence of opiates, cocaine, amphetamine, and cannabis. Finally, it was ascertained that the volunteers were free of hearing deficits (at frequencies of 500,1000, and $6000 \mathrm{~Hz}$ and intensities of 20 and $40 \mathrm{~dB}$ ).

Design and treatment. The design of the experiment was a double-blind, placebo-controlled, cross-over study, where an oral dose of $8 \mathrm{mg}$ reboxetine (Edronax, Pfizer), $2 \mathrm{mg}$ haloperidol (Serenase, Janssen), their combination or placebo (folic acid and/or C-vitamin) was administered to the 21 participants at four separate visits with a minimum of 2 weeks apart (to allow washout of the compounds). The dosages were chosen based on the guidelines for clinical treatment of first users (Kapur et al, 2000b; Preskorn, 2004). Previous studies have shown that peak plasma level of haloperidol is reached after $2-6 \mathrm{~h}$ following administration, while its terminal half-life is $\sim 24 \mathrm{~h}$ (Huang et al, 1996). For reboxetine, the maximum plasma level is reached within $2 \mathrm{~h}$ following oral intake, while its terminal half-life is $\sim 13 \mathrm{~h}$ (Hajos et al, 2004).

During each of the sessions, blood samples were taken from the subjects just before and immediately after the psychophysiological assessments to evaluate the plasma levels of the compounds in retrospective analysis. Furthermore, blood pressure was recorded and psychometric ratings of alertness were assessed with a visual analog scale (Bond, 1974) at fixed time intervals (see below).

The subjects arrived at the Center for Neuropsychiatric Schizophrenia Research, Glostrup academic hospital, at 09:00. They had been requested to fast from 23:00 of the preceding night and to abstain from caffeinated beverages $2 \mathrm{~h}$ before and from cigarette smoking $1 \mathrm{~h}$ before the psychophysiological assessments. This, in order to avoid effects of food intake on the pharmacokinetics of the compounds as well as to avoid acute or withdrawal effects of nicotine and caffeine. In addition, participants were requested not to consume any alcohol on the preceding day. The active compounds or placebo were administered orally in a white opaque capsule and subjects were requested to wait for $120 \mathrm{~min}$ to allow the compounds to reach maximal plasma levels (see above). Thereafter the subjects were tested in the Copenhagen Psychophysiological Test Battery, which consists of PPI, P50 suppression, mismatch negativity, and selective attention paradigms presented in that order (for more details see: Oranje and Glenthoj, 2013c; Jensen et al, 2008; Wienberg et al, 2010). In the current paper, only results on P50 suppression will be reported.

\section{Animal Study}

Animals. Male, Lister-Hooded rats (Charles River, The Netherlands) were used in all experiments. 
Housing consisted of a transparent, high, grid-lid macrolon cage, type III or IV (type IV GH; $54 \times 36 \times 18 \mathrm{~cm}$; type III IR; $37 \times 22 \times 18 \mathrm{~cm}$ ), with wood-chip bedding and environmental enrichment (plastic house and wooden chew blocks). All animals were housed under controlled temperature $\left(20 \pm 2{ }^{\circ} \mathrm{C}\right)$ and humidity conditions (30-70\%) with a reversed $12: 12 \mathrm{~h}$ light/dark cycle. Food and water were available ad libitum.

Treatment. Reboxetine (Abcam, Cambridge, UK) was dissolved in isotonic, slightly warmed water and haloperidol (Sigma-Aldrich, St Louis, MO, USA) was dissolved in saline to which a small amount of tartaric acid was added ( $\mathrm{pH}$ 5.5). The dosages administered in the rat study were carefully chosen in such a way that they were equivalent to the human dosages with respect to unbound peak plasma concentrations (reboxetine) and D2 occupancy (haloperidol). For haloperidol the rat equivalent of the human $2 \mathrm{mg}$ dose was $0.08 \mathrm{mg} /$ $\mathrm{kg}$, for reboxetine the rat equivalent of the human $8 \mathrm{mg}$ dose was $2 \mathrm{mg} / \mathrm{kg}$ reboxetine administered s.c. (see Supplementary Materials for more details).

\section{Human and Rat Gating Paradigms and Data Processing}

The human gating paradigm as well as its processing and assessment have been previously described (Oranje et al, 2013; Oranje and Glenthoj, 2013a). Similarly, the rat gating paradigm as well as its assessment and processing have been described before (Broberg et al, 2010; Witten et al, 2014) with the exception that the coordinates for electrode placement in the current rat study were: frontal cortex $(+3.0 \mathrm{~mm}$ anterior, $-0.5 \mathrm{~mm}$ lateral), ground $(-4.5 \mathrm{~mm}$ posterior, +4.0 lateral) and a depth electrode in CA-3 region of the hippocampus ( $-5.2 \mathrm{~mm}$ posterior to bregma, $-5.0 \mathrm{~mm}$ lateral, $-4.8 \mathrm{~mm}$ ventral to dura). Further changes to the gating paradigm in rats include a low pass-filter setting of $300 \mathrm{~Hz}$ in the recording session and $1.5 \mathrm{~ms}$ duration (instantaneous rise and fall time) of clicks. Please see the Supplementary Materials for more details.

\section{Statistical Analysis}

Statistical analysis was performed with SPSS (version 11.0; SPSS) for human data and SigmaPlot (version 11.0) for rat data. The human and rat data were normally distributed (Kolmogorov-Smirnov). The raw amplitudes of P50, N100, $\mathrm{P} 1$, and $\mathrm{N} 1$ were analyzed with two-way repeated measures analysis of variance (ANOVA), with within-factors 'treatment' (the four different treatments) and 'stimulus' ( $\mathrm{C}$ or $\mathrm{T}$ ) to find out whether suppression occurred and to see whether treatment had an effect on raw amplitude. The suppression data (T/C ratio) were analyzed with a one-way repeated measures ANOVA with the factor treatment to study the effect of treatment on P50, N100, P1, and N1 gating. In cases where the ANOVAs indicated statistical significance, post hoc Tukey tests were performed. Outlying values exceeding the mean by two SD were Winsorized (truncated) to values corresponding to $2 \mathrm{SD}$ from the mean (Dixon and Tukey, 1968).

In the animal data set one animal had to be excluded from the full analysis because the ERPs from the placebo treatment were missing. Furthermore, one data set was lost due to hardware problems.

In general, data are expressed as group mean \pm SEM unless otherwise stated. A $p$-value of $<0.05$ was regarded as statistically significant $(p<0.05)$.

\section{RESULTS}

\section{Humans}

P50. On raw amplitude level, the repeated-measures ANOVA showed a main effect of stimulus $(F(1,20)=85.37$, $p<0.001$; Figures 1 and 2; Table 1), indicating that the subjects' average amplitude to T-stimuli were significantly lower than that to C-stimuli, thus confirming that the paradigm performed as intended. Neither a main effect of treatment $(\mathrm{F}(3,18)=0.52, p=0.672)$ nor a stimulus by treatment
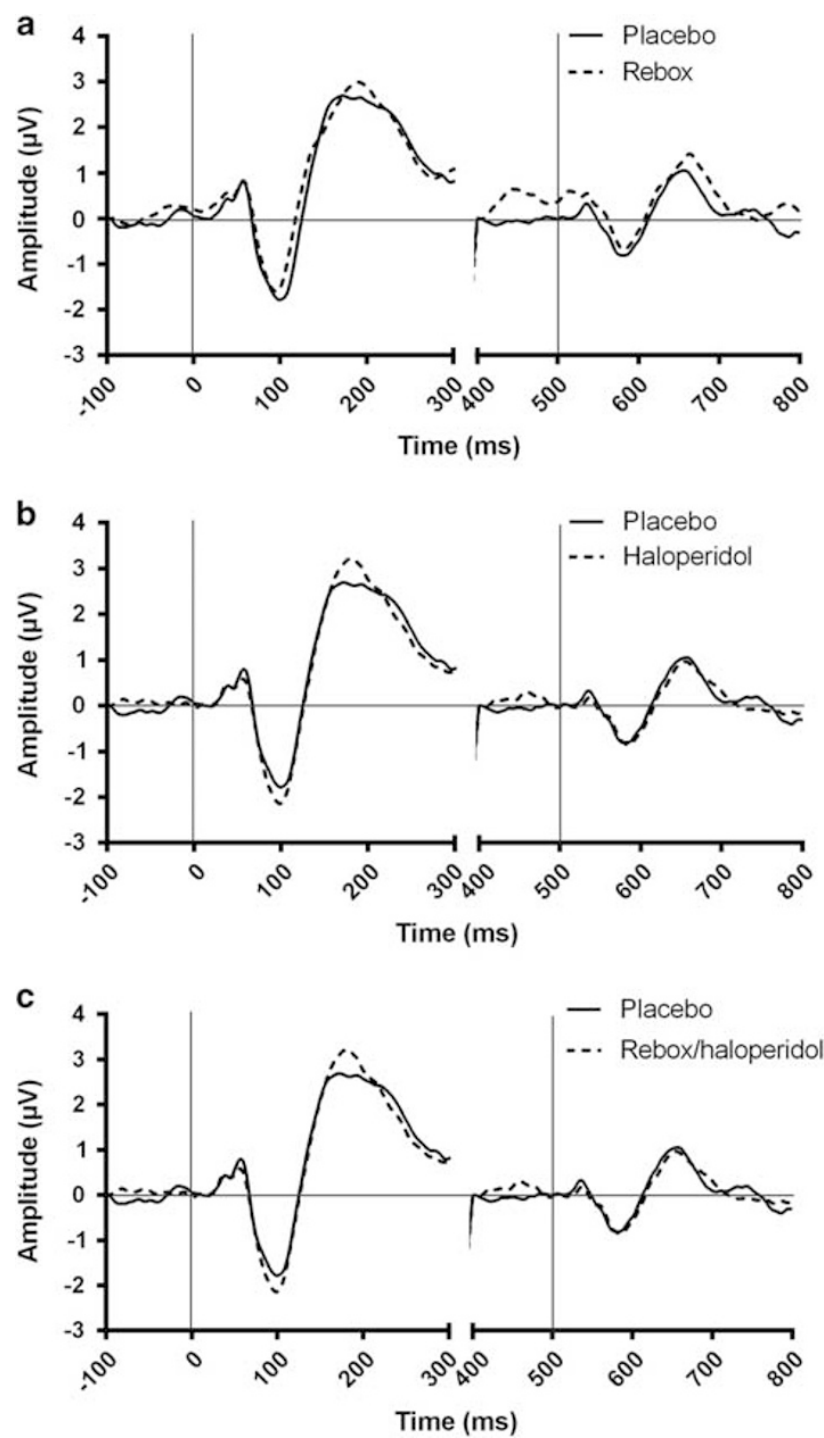

Figure I Grand averages of the auditory-evoked potentials in healthy human subjects. (a) Placebo/placebo and reboxetine/placebo, (b) placebo/ placebo and haloperidol/placebo, (c) placebo/placebo and haloperidol/ reboxetine. 

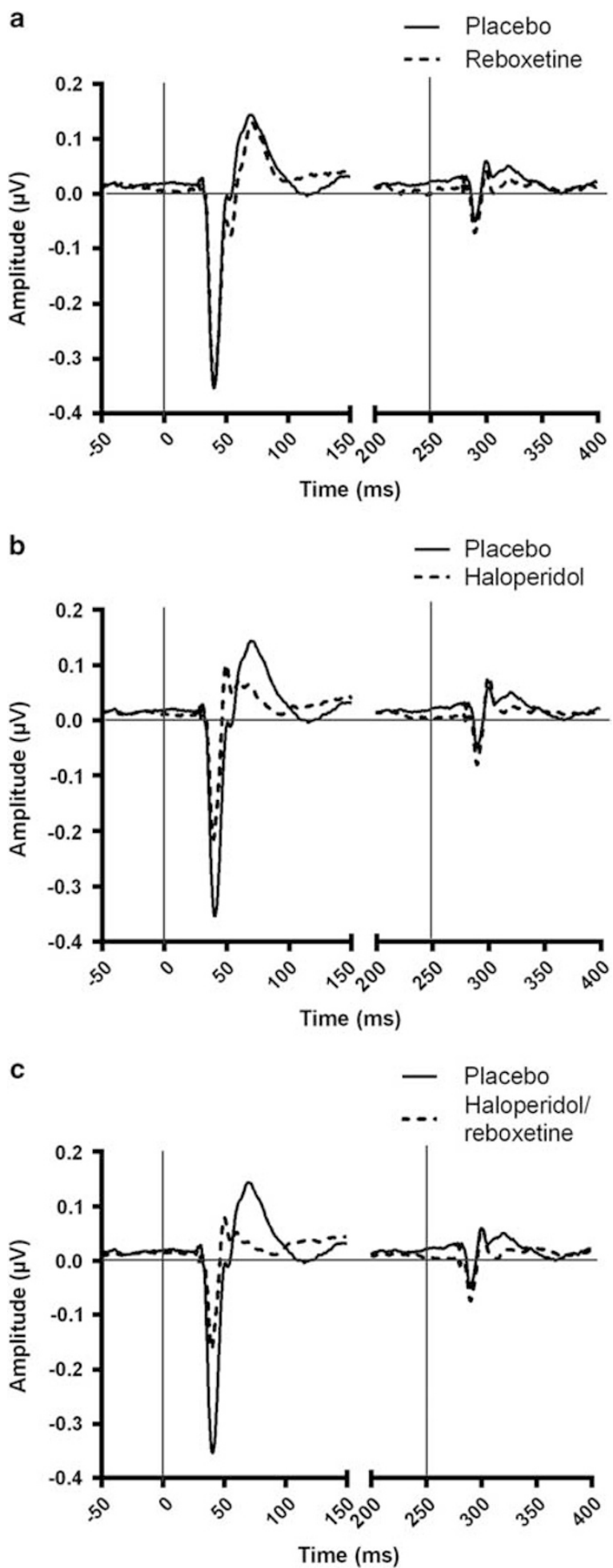

Figure 2 Grand averages of the auditory-evoked potentials in the hippocampus (CA3 area) of rats. (a) Placebo/placebo and reboxetine/ placebo, (b) placebo/placebo and haloperidol/placebo, (c) placebo/placebo and haloperidol/reboxetine.

interaction effect $(F(3,60)=0.92, p=0.437)$ were found (see Figure 3a).

In the suppression data ( $\mathrm{T} / \mathrm{C}$ ratio) repeated-measures ANOVA revealed a main effect of treatment $(\mathrm{F}(3,18)=5.00$, $p=0.011$ ). Further analysis (post hoc Tukey's tests) revealed that the T/C ratio of haloperidol/placebo $(p=0.032)$ and reboxetine/placebo $(p=0.046)$ treatments were significantly higher than in the placebo/placebo treatment, while the increased ratio in the haloperidol/reboxetine did not reach statistical significance $(p=0.103)$ compared with placebo/ placebo (see Figure 4a).

N100. Repeated-measures ANOVA showed a main effect of stimulus $(F(1,20)=23.04, p<0.001)$, indicating that the subjects' average amplitude to $\mathrm{T}$-stimuli were significantly lower than to C-stimuli. Neither a main effect of treatment $(\mathrm{F}(3,20)=2.25, p=0.91)$ nor stimulus by treatment interaction effect $(\mathrm{F}(3,60)=1.17, p=0.329)$ were found on raw amplitude level. No significant treatment effects were found for the T/C ratio of the $\mathrm{N} 100(\mathrm{~F}(3,18)=1.252, p=0.320$; see Figures $3 \mathrm{a}$ and $4 \mathrm{a})$.

\section{Rats}

\section{Hippocampus}

P1. On raw amplitude level, a main effect of stimulus $(\mathrm{F}(1,19)=8.22, p=0.010)$ was found, showing that the subjects' average amplitude to T-stimuli were significantly lower than to C-stimuli. Neither a main effect of treatment $(\mathrm{F}(3,19)=0.48, p=0.698)$ nor stimulus by treatment interaction effect $(\mathrm{F}(3,57)=0.27, p=0.848)$ were found. No significant treatment effects were found $(\mathrm{F}(3,17)=0.26$, $p=0.878$ ) in the T/C ratio of P1 (see Figures $3 \mathrm{~b}$ and $4 \mathrm{~b}$ ).

N1. On raw amplitude level, a main effect of stimulus $(\mathrm{F}(1,19)=88.44, p<0.001)$ was found, showing that the subjects' average amplitude to T-stimuli were significantly lower than that to $\mathrm{C}$-stimuli, therewith confirming that the paradigm worked as intended. Neither a main effect of treatment $(\mathrm{F}(3,19)=1.06, p=0.375)$ nor a stimulus by treatment interaction effect $(\mathrm{F}(3,57)=1.76, p=0.166)$ were found (see Figure 3b).

Repeated-measures ANOVA on the T/C ratios revealed a significant effect of treatment $(\mathrm{F}(3,17)=10.16, p<0.001)$. Further analysis (post hoc Tukey's tests) revealed that the T/C ratio in haloperidol/placebo $(p<0.001)$ and haloperidol/ reboxetine $(p=0.005)$ treatments were significantly higher than in the placebo/placebo treatment, but the reboxetine/ placebo treatment was not significantly different $(p>0.05$; see Figure $4 \mathrm{~b}$ ).

Latencies. No significant treatment differences in the latencies of the above mentioned ERPs were found in either rats or humans (data not shown).

\section{DISCUSSION}

In the current study, we tested the effects of reboxetine, haloperidol, and their combination on auditory sensory gating in healthy male humans and rats. Whereas all three active treatments reduced P50 gating in healthy males compared with placebo, this only reached statistical significance in the case of the separate reboxetine and haloperidol treatments. No significant effect of treatment was found on human N100 gating compared with placebo. In rats, haloperidol and the combination of haloperidol and reboxetine 
Table I Average Raw Amplitude Data Expressing Amplitudes to C (Conditioning) and T (Testing) Stimuli, as well as the T/C Ratio Showing Suppression

\begin{tabular}{|c|c|c|c|c|c|}
\hline Subject & Treatment & ERP & C amplitudes & T amplitudes & $\mathrm{T} / \mathrm{C}$ ratio \\
\hline \multirow[t]{6}{*}{ Humans } & Placebo/placebo & P50 & $1.60(0.19)$ & $0.22(0.05)$ & $0.15(0.04)$ \\
\hline & & NIOO & $-2.43(0.37)$ & $-1.12(0.18)$ & $0.58(0.10)$ \\
\hline & Reboxetine/placebo & $\mathrm{P} 50$ & $1.41(0.18)$ & $0.34(0.09)$ & $0.29(0.06)$ \\
\hline & & NIOO & $-2.22(0.42)$ & $-0.87(0.22)$ & $0.58(0.10)$ \\
\hline & Haloperidol/placebo & P50 & $1.42(0.19)$ & $0.35(0.09)$ & $0.27(0.06)$ \\
\hline & & NIOO & $-2.43(0.33)$ & $-1.30(0.17)$ & $0.77(0.20)$ \\
\hline \multirow[t]{4}{*}{ Rats } & Placebo/placebo & $\mathrm{Pl}$ & $0.08(0.04)$ & $0.03(0.01)$ & $0.80(0.13)$ \\
\hline & & NI & $-0.29(0.05)$ & $-0.10(0.02)$ & $0.30(0.04)$ \\
\hline & Reboxetine/placebo & $\mathrm{Pl}$ & $0.06(0.02)$ & $0.03(0.01)$ & $0.59(0.06)$ \\
\hline & & $\mathrm{NI}$ & $-0.23(0.04)$ & $-0.10(0.02)$ & $0.53(0.06)$ \\
\hline
\end{tabular}

Data are expressed in microvolts $( \pm$ SEM).

a
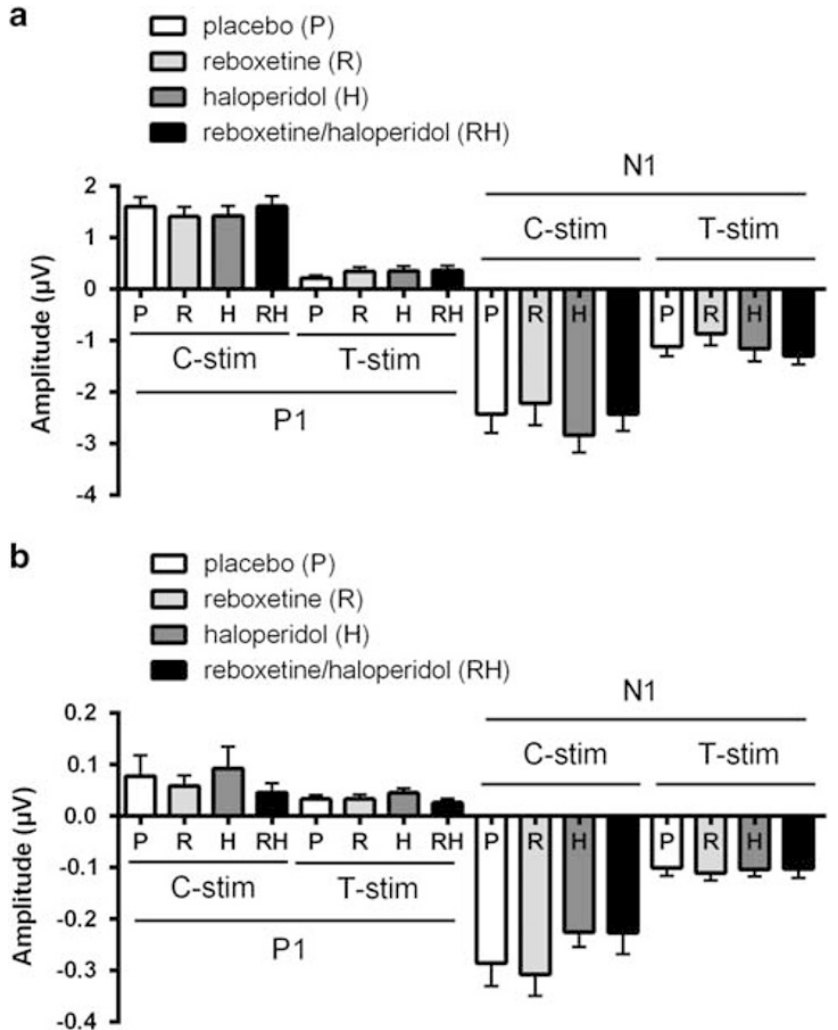

Figure 3 Individual peak amplitudes for $\mathrm{PI}$ and $\mathrm{NI} \pm$ SEM of (a) humans and (b) rats (hippocampus) (Cz). $\mathrm{P}=$ placebo/placebo, $\mathrm{R}=$ reboxetine/ placebo, $\mathrm{H}=$ haloperidol/placebo, $\mathrm{RH}=$ reboxetine/haloperidol.

significantly reduced $\mathrm{N} 1$ gating in the hippocampus (CA3 region) compared with placebo, while reboxetine alone did not affect N1 gating. No effect of treatment was seen on P1 gating.
Our finding that reboxetine has a disruptive effect on P50 gating in healthy males is in alignment with previous studies investigating the effect of increased NE activity in healthy volunteers such as the effect of yohimbine (Adler et al, 1994) or imipramine (Hammer et al, 2007). As reboxetine is a selective blocker of NET in humans and rats (Hajos et al, 2004), its disruptive effect on human P50 gating supports involvement of the NE system in sensory gating. However, in rats we found no effects of reboxetine. A previous study investigating the effects of yohimbine (selective $\alpha$-2 noradrenergic antagonist) reported disrupted gating in rats (Stevens et al, 1993), indicating that also in rats increased $\mathrm{NE}$ activity can lead to impaired gating. Our negative finding may be explained by the fact that we calculated the rat dose of reboxetine from our human plasma levels: we have, therefore, no information on how the human and rat doses relate to receptor occupancy in the brain.

Haloperidol disrupted P50 gating in our human subjects compared with placebo treatment. Although there are many studies showing that haloperidol and the other typical antipsychotics do not seem to influence disrupted sensory gating in patients with schizophrenia (Adler et al, 2004; Arango et al, 2003; Becker et al, 2004), only a few studies investigated healthy human subjects on this matter. A previous study from our laboratory somewhat supports that haloperidol disrupts gating in healthy humans (Oranje et al, 2002). In another study, haloperidol increased P50 suppression in subjects exhibiting low levels of P50 gating yet disrupted it in subjects expressing high levels (Csomor et al, 2008), indicating that blocking dopamine-D2 receptors affect sensory gating in healthy humans. Considering these two studies and the fact that healthy males usually score high levels of P50 gating, it may explain why we, in the current study, find that haloperidol reduced average P50 gating. Therefore, although other recent data from our lab showed that P50 suppression deficits are already present in 
a

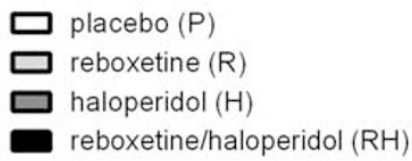

P50

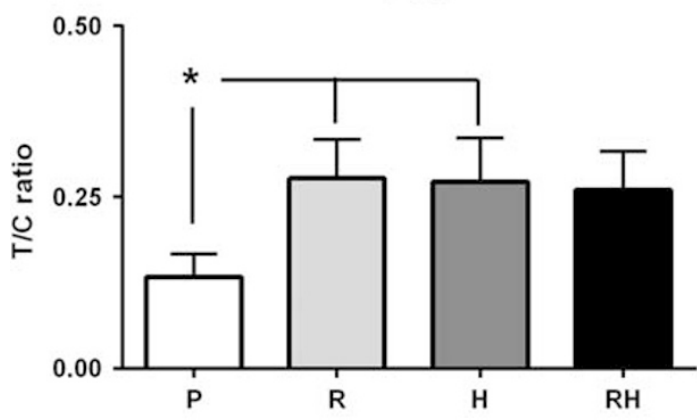

b

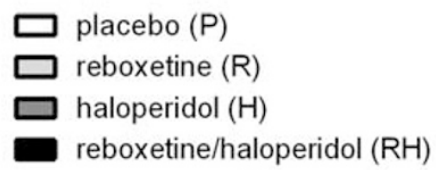

P1

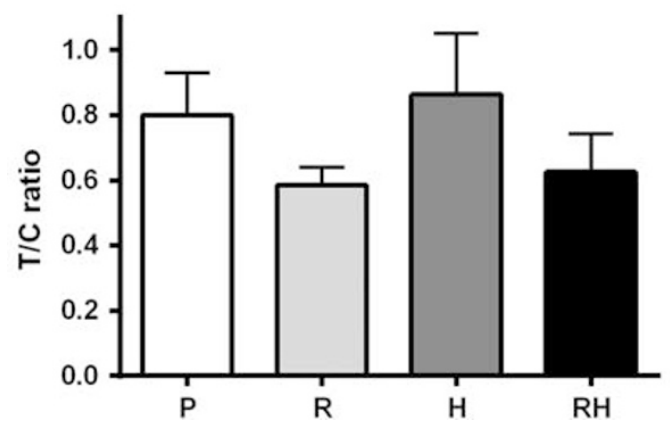

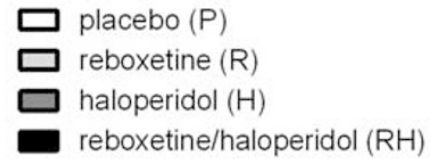

N100
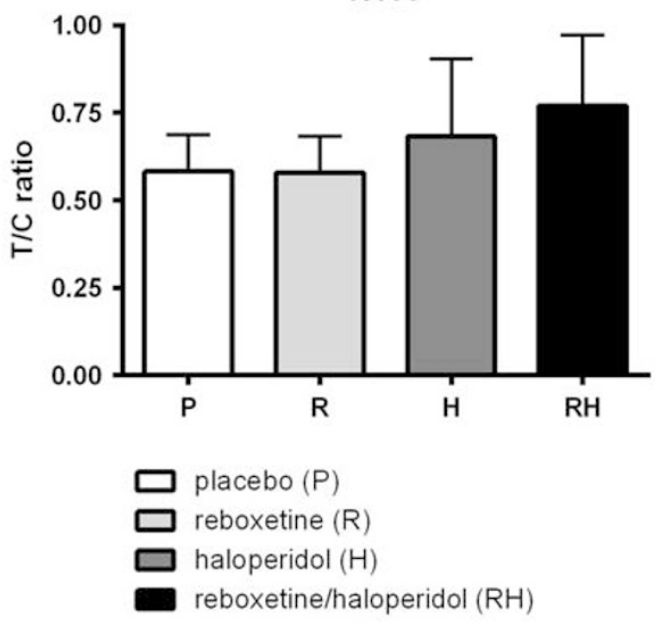

N1

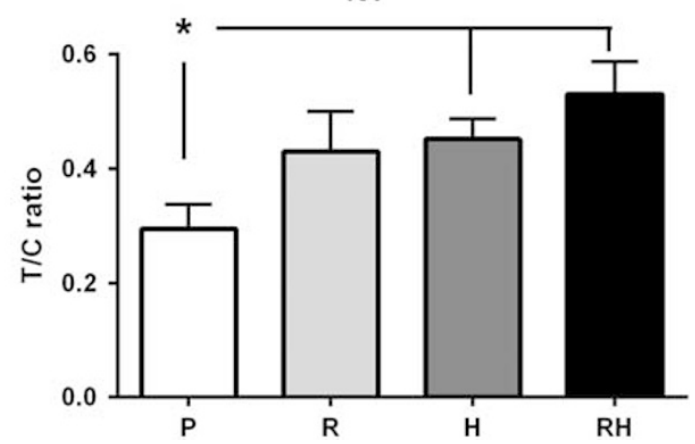

Figure $4 \mathrm{~T} / \mathrm{C}$ ratio $( \pm \mathrm{SEM}$ ) of placebo/placebo, reboxetine/placebo, haloperidol/placebo and reboxetine/haloperidol in PI/P50 and NI/NI00 of (a) humans showing significantly increased $\mathrm{T} / \mathrm{C}$ ratio in the reboxetine/placebo and haloperidol/placebo treatments compared with placebo/placebo and (b) rats (hippocampus) showing significant increased T/C ratio of NI gating with haloperidol/placebo and haloperidol/reboxetine treatment compared with placebo/placebo. $* P<0.05$.

antipsychotic naive, first-episode patients with schizophrenia (eg, Oranje et al, 2013), our current data raise the possibility that D2 antagonism may contribute to the P50 suppression deficits reported from studies on medicated patients with schizophrenia.

Similar to our human P50 gating data, haloperidol disrupted gating (N1) in the hippocampus of rats.

In previous animal studies, haloperidol is mainly used in gating experiments to antagonise the disruptive effects of, eg, amphetamine, phencyclidine, and morphine (Adler et al, 1986; Zheng et al, 2005). The few studies that have investigated haloperidol's effect alone have shown either no effect (Ma et al, 2009) or improved gating (Anstrom et al, 2007) with administration of $1 \mathrm{mg} / \mathrm{kg}$ haloperidol using intraperitoneal or intramuscular injections, respectively. As this dose of haloperidol has been found to result in a D2 occupancy level above $80 \%$, which may induce extrapyramidal side effects such as catalepsy (Kapur et al, 2000a), comparison between studies remains difficult.

Given that the compounds administered separately significantly disrupted P50 gating in our human volunteers, it was surprising to find that the combination did not significantly affect their gating levels. This indicates that the combination of compounds does not have a synergistic or additive effect. This can be due to a simple power issue of the study or it may be that a pharmacodynamic interaction is involved in this discrepancy. For instance, it has been shown that haloperidol significantly reduces baseline levels of $\mathrm{NE}$ in rats (Amato et al, 2011). A growing body of evidence has indicated that an optimal functional PFC is essential for normal levels of gating (Bak et al, 2011; Oranje et al, 2006, 2013; Weisser et al, 2001). Interestingly, there is no dopamine transporter in the rat PFC, nor in humans as a matter of fact: dopamine in the PFC is removed by NET (Carboni et al, 1990; Pozzi et al, 1994). Given this, it may be that the two compounds counterbalance each other's action in the PFC. In contrast, in rats we actually did find a significant reduction of (N1) gating with administration of reboxetine and haloperidol. However, as we found no significant effect of separate reboxetine treatment this may indicate that the observed disruption is solely due to the effect of haloperidol suggesting that the theorized human counterbalance effect from the two compounds is not evident in rats. 
When back-translating the human results to the rat there are certain things to take into consideration. These include that the pattern of rat ERPs in our P50 suppression paradigm displays remarkable similarities with that of humans. Therefore, one would expect the P50 peak in humans to be equivalent to the P13 in rats, whereas the human N100 would be equivalent to the rat N40. However, in human studies mainly P50 suppression is reported, while in rats mainly N40 gating is observed, which is in line with what we find in the current study, where pharmacological disruption occurred of human P50 and rat N40. Speculatively, it may be that the shorter latencies of the rat ERPs compared with the human ERPs make the expression of gating occur at a later latency in the rat EEG than in the human EEG.

In rats, we had additional recording electrodes placed on the skull to record cortical activity, besides having inserted a depth electrode in the CA3 area of the hippocampus. Nevertheless, it was only at the hippocampal site that we obtained a significant treatment effect on gating (see Supplementary Material for cortical data). The signals recorded from the hippocampus might be more 'pure' in the sense that one avoids the noise generated in other areas of the brain that could have been picked up by the large low impedance surface screw electrodes. Another explanation may come from the accumulating evidence for a role of the hippocampus, beside that of the PFC, in the inhibitory processes underlying P50 suppression (Bak et al, 2011; Miller and Freedman, 1995), which might explain why our treatment effect was mostly evident in this area. Nevertheless, this lack of direct cortical to cortical back-translation calls for a more detailed investigation of the translational value of sensory gating in human-to-rat studies.

There are strengths but also limitations to the current study. An obvious strength is that we, in contrast to many other studies, made a serious attempt to keep the experimental conditions between our human and rat studies as identical as possible, ie, we used identical paradigms and tried to reach identical plasma levels of the active compounds in both species. In spite of our efforts, however, there are of course factors that were not possible to change: rats were able to move freely, whereas the humans were instructed to sit still in a chair. As excitatory neurons in the auditory cortex of behaving mice have been shown to be suppressed before and during movement (Schneider et al, 2014) this may also have influenced our data. A further limitation may be that we have only investigated acute doses of the compounds, from which it is difficult to predict the effects of chronic treatment of the compounds, such as usually is the case in clinical settings. In conclusion, our data show that haloperidol disrupts gating in human cortex and rat hippocampus, while reboxetine only disrupts gating in humans but not in rats. The combination of the two compounds had no significant effect on human gating, while it significantly reduced gating in rats. Our study indicates that even when experimental conditions are kept as similar as possible, direct cross-species translation of pharmacological effects on sensory gating can only be marginally established, which calls for more focussed research in this important translational area.

\section{FUNDING AND DISCLOSURE}

The authors declare no conflict of interest.

\section{ACKNOWLEDGMENTS}

We wish to thank Kasper Larsen for his contribution to the animal part of this study, and Gitte Saltoft Andersen and Katherina Alfsen for their valuable contribution to the human part of our study.

\section{REFERENCES}

Adler LE, Hoffer L, Nagamoto HT, Waldo MC, Kisley MA, Giffith JM (1994). Yohimbine impairs P50 auditory sensory gating in normal subjects. Neuropsychopharmacology 10: 249-257.

Adler LE, Olincy A, Cawthra EM, McRae KA, Harris JG, Nagamoto HT et al (2004). Varied effects of atypical neuroleptics on P50 auditory gating in schizophrenia patients. Am J Psychiatry 161: 1822-1828.

Adler LE, Pachtman E, Franks RD, Pecevich M, Waldo MC, Freedman R (1982). Neurophysiological evidence for a defect in neuronal mechanisms involved in sensory gating in schizophrenia. Biol Psychiatry 17: 639-654.

Adler LE, Rose G, Freedman R (1986). Neurophysiological studies of sensory gating in rats: effects of amphetamine, phencyclidine, and haloperidol. Biol Psychiatry 21: 787-798.

Amato D, Natesan S, Kapur S, Muller CP (2011). Haloperidol modulates noradrenergic responses to aversive stimulation depending on treatment duration. Behav Brain Res 221: 311-313.

Anstrom KK, Cromwell HC, Woodward DJ (2007). Effects of restraint and haloperidol on sensory gating in the midbrain of awake rats. Neuroscience 146: 515-524.

Arango C, Summerfelt A, Buchanan RW (2003). Olanzapine effects on auditory sensory gating in schizophrenia. Am J Psychiatry 160: 2066-2068.

Bak N, Glenthoj BY, Rostrup E, Larsson HB, Oranje B (2011). Source localization of sensory gating: a combined EEG and fMRI study in healthy volunteers. Neuroimage 54: 2711-2718.

Baker NJ, Staunton M, Adler LE, Gerhardt GA, Drebing C, Waldo $M$ et al (1990). Sensory gating deficits in psychiatric inpatients: relation to catecholamine metabolites in different diagnostic groups. Biol Psychiatry 27: 519-528.

Becker J, Gomes I, Ghisolfi ES, Schuch A, Ramos FL, Ehlers JA et al (2004). Clozapine, but not typical antipsychotics, correct P50 suppression deficit in patients with schizophrenia. Clin Neurophysiol 115: 396-401.

Bond A, Lader M (1974). The use of analogue scales in rating subjective feelings. Br J Med Psychol 47: 211-218.

Boutros NN, Belger A, Campbell D, D'Souza C, Krystal J (1999). Comparison of four components of sensory gating in schizophrenia and normal subjects: a preliminary report. Psychiatry Res 88: $119-130$.

Boutros NN, Korzyukov O, Jansen B, Feingold A, Bell M (2004). Sensory gating deficits during the mid-latency phase of information processing in medicated schizophrenia patients. Psychiatry Res 126: 203-215.

Bramon E, Rabe-Hesketh S, Sham P, Murray RM, Frangou S (2004). Meta-analysis of the P300 and P50 waveforms in schizophrenia. Schizophr Res 70: 315-329.

Broberg BV, Oranje B, Glenthoj BY, Fejgin K, Plath N, Bastlund JF (2010). Assessment of auditory sensory processing in a neurodevelopmental animal model of schizophrenia-gating of auditory-evoked potentials and prepulse inhibition. Behav Brain Res 213: 142-147.

Brockhaus-Dumke A, Mueller R, Faigle U, Klosterkoetter J (2008). Sensory gating revisited: relation between brain oscillations and auditory evoked potentials in schizophrenia. Schizophr Res 99: 238-249. 
Carboni E, Tanda GL, Frau R, Di CG (1990). Blockade of the noradrenaline carrier increases extracellular dopamine concentrations in the prefrontal cortex: evidence that dopamine is taken up in vivo by noradrenergic terminals. J Neurochem 55: 1067-1070.

Chang WP, Arfken CL, Sangal MP, Boutros NN (2011). Probing the relative contribution of the first and second responses to sensory gating indices: a meta-analysis. Psychophysiology 48: 980-992.

Csomor PA, Stadler RR, Feldon J, Yee BK, Geyer MA, Vollenweider FX (2008). Haloperidol differentially modulates prepulse inhibition and p50 suppression in healthy humans stratified for low and high gating levels. Neuropsychopharmacology 33: 497-512.

Dixon WJ, Tukey JW (1968). Approximate behavior of distribution of winsorized T (Trimming/Winsorization 2). Technometrics 10: 83-98.

Hajos M, Fleishaker JC, Filipiak-Reisner JK, Brown MT, Wong EH (2004). The selective norepinephrine reuptake inhibitor antidepressant reboxetine: pharmacological and clinical profile. CNS Drug Rev 10: 23-44.

Hammer TB, Oranje B, Glenthoj BY (2007). The effects of imipramine on P50 suppression, prepulse inhibition and habituation of the startle response in humans. Int J Neuropsychopharmacol 10: 787-795.

Huang HF, Jann MW, Wei FC, Chang TP, Chen JS, Juang DJ et al (1996). Lack of pharmacokinetic interaction between buspirone and haloperidol in patients with schizophrenia. J Clin Pharmacol 36: $963-969$.

Jensen KS, Oranje B, Wienberg M, Glenthoj BY (2008). The effects of increased serotonergic activity on human sensory gating and its neural generators. Psychopharmacology (Berl) 196: 631-641.

Jin Y, Bunney WE Jr, Sandman CA, Patterson JW, Fleming K, Moenter JR et al (1998). Is P50 suppression a measure of sensory gating in schizophrenia? Biol Psychiatry 43: 873-878.

Kapur S, Wadenberg ML, Remington G (2000a). Are animal studies of antipsychotics appropriately dosed? Lessons from the bedside to the bench. Can J Psychiatry 45: 241-246.

Kapur S, Zipursky R, Jones C, Remington G, Houle S (2000b). Relationship between dopamine $\mathrm{D}(2)$ occupancy, clinical response, and side effects: a double-blind PET study of first-episode schizophrenia. Am J Psychiatry 157: 514-520.

Light GA, Braff DL (1999). Human and animal studies of schizophrenia-related gating deficits. Curr Psychiatry Rep 1: 31-40.

Ma J, Tai SK, Leung LS (2009). Ketamine-induced deficit of auditory gating in the hippocampus of rats is alleviated by medial septal inactivation and antipsychotic drugs. Psychopharmacology (Berl) 206: 457-467.

Mears RP, Klein AC, Cromwell HC (2006). Auditory inhibitory gating in medial prefrontal cortex: single unit and local field potential analysis. Neuroscience 141: 47-65.

Miller CL, Freedman R (1995). The activity of hippocampal interneurons and pyramidal cells during the response of the hippocampus to repeated auditory stimuli. Neuroscience 69: 371-381.

Miyazato H, Skinner RD, Garcia-Rill E (1999). Neurochemical modulation of the P13 midlatency auditory evoked potential in the rat. Neuroscience 92: 911-920.
Nagamoto HT, Adler LE, Waldo MC, Freedman R (1989). Sensory gating in schizophrenics and normal controls: effects of changing stimulation interval. Biol Psychiatry 25: 549-561.

Oranje B, Aggernaes B, Rasmussen H, Ebdrup BH, Glenthoj BY (2013). P50 suppression and its neural generators in antipsychotic-naive first-episode schizophrenia before and after 6 months of quetiapine treatment. Schizophr Bull 39: 472-480.

Oranje B, Geyer MA, Bocker KB, Leon KJ, Verbaten MN (2006). Prepulse inhibition and P50 suppression: commonalities and dissociations. Psychiatry Res 143: 147-158.

Oranje B, Gispen-de Wied CC, Verbaten MN, Kahn RS (2002). Modulating sensory gating in healthy volunteers: the effects of ketamine and haloperidol. Biol Psychiatry 52: 887-895.

Oranje B, Glenthoj BY (2013a). Clonidine normalizes levels of P50 gating in patients with schizophrenia on stable medication. Schizophr Bull 40: 1022-1029.

Oranje B, Glenthoj BY (2013b). Clonidine normalizes sensorimotor gating deficits in patients with schizophrenia on stable medication. Schizophr Bull 39: 684-691.

Oranje B, Glenthoj BY (2013c). Clonidine normalizes sensorimotor gating deficits in patients with schizophrenia on stable medication. Schizophr Bull 39: 684-691.

Pozzi L, Invernizzi R, Cervo L, Vallebuona F, Samanin R (1994). Evidence that extracellular concentrations of dopamine are regulated by noradrenergic neurons in the frontal cortex of rats. I Neurochem 63: 195-200.

Preskorn SH (2004). Reboxetine: a norepinephrine selective reuptake pump inhibitor. J Psychiatr Pract 10: 57-63.

Schneider DM, Nelson A, Mooney R (2014). A synaptic and circuit basis for corollary discharge in the auditory cortex. Nature 513: 117-171.

Siegel SJ, Connolly P, Liang Y, Lenox RH, Gur RE, Bilker WB et al (2003). Effects of strain, novelty, and NMDA blockade on auditory-evoked potentials in mice. Neuropsychopharmacology 28: $675-682$.

Stevens KE, Meltzer J, Rose GM (1993). Disruption of sensory gating by the alpha 2 selective noradrenergic antagonist yohimbine. Biol Psychiatry 33: 130-132.

Weisser R, Weisbrod M, Roehrig M, Rupp A, Schroeder J, Scherg M (2001). Is frontal lobe involved in the generation of auditory evoked P50? Neuroreport 12: 3303-3307.

Wienberg M, Glenthoj BY, Jensen KS, Oranje B (2010). A single high dose of escitalopram increases mismatch negativity without affecting processing negativity or P300 amplitude in healthy volunteers. J Psychopharmacol 24: 1183-1192.

Wing JK, Babor T, Brugha T, Burke J, Cooper JE, Giel R et al (1990). SCAN. Schedules for clinical assessment in neuropsychiatry. Arch Gen Psychiatry 47: 589-593.

Witten L, Oranje B, Mork A, Steiniger-Brach B, Glenthoj B, Bastlund JF (2014). Auditory sensory processing deficits in sensory gating and mismatch negativity-like responses in the social isolation rat model of schizophrenia. Behav Brain Res 266: 85-93.

Zheng J, Yang Y, Tian S, Chen J, Wilson FA, Ma Y (2005). The dynamics of hippocampal sensory gating during the development of morphine dependence and withdrawal in rats. Neurosci Lett 382: $164-168$.

Supplementary Information accompanies the paper on the Neuropsychopharmacology website (http://www.nature.com/npp) 